\title{
INTERTEXTUALIDAD Y SISTEMA EN LAS VARIANTES DE BORGES
}

La afirmación con la que Borges presenta al público, en 1969, la versión corregida de Fervor de Buenos Aires ${ }^{1}$ - "No he reescrito el libro"- es al mismo tiempo paradójica y mendaz. Es paradójica porque afirma implícitamente la posibilidad de reescribir a los setenta años un libro de poesías escrito a los veinticuatro, y es mendaz porque niega explícitamente que tal operación haya sido intentada, al menos de alguna manera. La nueva versión es, en efecto, el resultado de una refundición que afecta aproximadamente al $45 \%$ de los versos y que constituye además la sexta transformación del libro a lo largo de veintisiete años. Una dedicación tan obstinada parece responder a una imperiosa exigencia de reapropiarse continuamente del propio producto, por lo que no sorprende que a la de 1969 Borges haga seguir otras tres revisiones más ${ }^{2}$. Por su alcance y su frecuencia, el proceso de estas revisiones presenta un relevante interés, ya que determina una serie de estratificaciones textuales más propias de la fase genética que de la evolutiva de una obra. Y ello hace por lo menos discutible que se pueda seguir dando la fecha de 1923 a esa opera prima,

${ }^{1}$ Emecé, Buenos Aires, 1969 (colección Obra poética de Borges). Se trata de la segunda edición en volumen suelto después de la de Serrantes de 1923. Las indicaré respectivamente con las siglas $E F 69$ y $S$.

${ }^{2}$ Las otras ediciones en las que Fervor de Buenos Aires presenta variantes son: Poemas (1922-1943), Losada, 1943; Poemas (1923-1953), Emecé, 1954; Poemas (1923-1958), Emecé, 1958; Obra poética (1923-1964), Emecé, 1964; Obra poética (1923-1966), Emecé, 1966; Obra poética (1923-1969), Emecé, 1972; Obras completas (1923-1972), Emecé, 1974; Obra poética (1923-1976), Emecé, 1977. Las citaré utilizando las siglas: L43,E54, E58, E64,E66, E72, E74, E77. Tales siglas identifican también las reediciones de Luna de enfrente (Proa, 1925) y Cuaderno San Martín (Proa, 1929); también estas dos recopilaciones fueron editadas en 1969 en volumen único en la colección Obra poética de Borges; uso la sigla ELC69. 
pero en continua gestación. El problema para el crítico es, por lo tanto, de método: en otras palabras, ¿es correcto estudiar las lecciones originales prescindiendo del proceso evolutivo al que están destinadas? o, al contrario, ¿'lo es estudiar las finales sin tener en cuenta la historia que las ha producido? Personalmente considero que cuestiones como ésta inducen más al análisis de la actividad del autor, que al de su producto; es decir, al estudio de la trayectoria evolutiva de los textos, de sus pequeñas o grandes metamorfosis, con el objetivo de identificar y describir, en la medida de lo posible, los mecanismos que determinan la reescritura.

He intentado señalar en otro lugar los aspectos característicos del proceso variantístico que afectó a las tres recopilaciones poéticas de los años veinte y de identificar las líneas correctivas más señaladas $^{3}$. Ahora pretendo ocuparme de algunos temas no desarrollados en aquella ocasión, limitándome sólo a Fervor. En particular, creo que merecen una observación más atenta las dinámicas intertextuales que se hallan en la base de las enmiendas, para verificar la medida en la que determinan (o contribuyen a determinar) la exigencia de modificar el texto, y el modo en que orientan o condicionan las soluciones correctivas. Se trata en resumidas cuentas, de investigar, partiendo de un cuadro general de las tendencias y de las finalidades que subyacen a la revisión, las microhistorias de las variantes, para que a través de éstas puedan ser identificadas las razones textuales que plasman en determinadas formas esas finalidades generales. Me parece que puede considerarse preliminarmente que el mecanismo de conjunto con el que se conectan los cambios es el de una interrelación dinámica y productiva entre las operaciones implicadas del acto de revisón, es decir, relectura, confirmación o abandono de la lección y reescritura, y entre esta última y la entidad textual

${ }^{3}$ Cf. T. Scarano, "Per uno studio delle varianti del primo Borges", introd. a Varianti a stampa nella poesia del primo Borges, Giardini, Pisa, 1987. Sobre el tema véase también G. Videla, "El sentido de las variantes textuales en dos ediciones de Fervor de Buenos Aires de J. L. Borges", RChL, 23 (1984), 67-78; aunque este ensayo se limita al examen de dos textos y se basa en el cotejo entre la primera edición y la intermedia de 1974. Para un inventario de las variantes de El hacedor y El otro, el mismo véanse T. SCARANo, "Ancora su variantistica borgesiana. La produzione poetica dal 1930 al 1967", StI, 1990. Del mismo autor: "Calle desconocida de J. L. Borges. Analisi delle varianti", en Symbolae Pisanae. Studi in onore di Guido Mancini, a cura di B. Periñán e F. Guazzelli, Giardini, Pisa, 1989, pp. 575-589. 
constituida por los productos de la actividad de escritura coetánea o más próxima a la corrección. Se intentará, por lo tanto, describir cómo y en qué medida se establecen condicionamientos entre reescritura y reescritura (por coherencia y analogía, o por compensaciones e inversiones), entre, reescritura y escritura (en ambas direcciones: o sea, de los textos de nueva composición a las modificaciones de los textos antiguos y viceversa, de éstos a composiciones posteriores), así como valorar si en la reescritura influye de algún modo la relectura de otros textos - corregidos o no- del conjunto sometido a revisión. Orientada de este modo, la investigación permitirá identificar, sobre la base de la peculiaridad de las relaciones que las variantes mantienen entre ellas y con el sistema completo de las modificaciones, algunas modalidades pragmáticas de la operación correctiva; reconstruir en conclusión, al menos como hipótesis y de forma parcial, el método de trabajo de Borges.

\section{De la ReEscritura a LA REESCritura}

Una disertación acerca de las dinámicas internas de las operaciones de reescritura no puede dejar de partir del caso más elemental y evidente de condicionamiento, el que se manifiesta, en la sincronía de la revisión, bajo la forma de repetición de un mismo cambio. Casi siempre las cuestiones de este tipo hay que atribuirlas a motivos estrechamente léxicos, y por regla general se confirman con el abandono progresivo o con la gradual incorporación de un cierto término. Las muestras examinables son numerosas, y pueden reunirse tipológicamente en tres grupos, según cuál sea el término recurrente: el abandonado, el introducido $\mathrm{o}$ ambos. Por poner algún ejemplo de casos simples, se pueden citar al paso, en L43, de combadura a curva tanto en "El jardín botánico", v. 7 ("como dobladas por la combadura celeste") como en "Plaza San Martín", v. 13 ("cuyas piadosas combaduras"); el desplazamiento repleto $\longrightarrow$ poblado llevado a cabo, en E64, en tres poemas: "Benarés", v. 39, "Campos atardecidos", v. 3 y «Fundación mitológica de Buenos Aires», v. $11(C S M)^{4}$;

${ }^{4}$ Todos los textos citados, excepto los de Fervor de Buenos 'Aires (FBA), irán acompañados de la referencia a la recopilación a la que pertenecen. Utilizaré las siguientes siglas: LE (Luna de enfrente), CSM (Cuaderno San Martin), $H_{\text {. }}$ (El Hacedor, 1960), OM (El otro, el mismo, 1964, pero que comprende poemas 
la modificación hoy $\longrightarrow$ ahora en "Inscripción sepulcral», v. 9 y "Rosas», v. 36 (EF69). Mayor relieve asume la doble sustitución en sincronía de realizar, primero (L43) y de resentir, después (EF69), en "La Recoleta", v. 37 ("lo realicé en la Recoleta", $\longrightarrow$ "lo resentí en la Recoleta" $\longrightarrow$ "Estas cosas pensé en la Recoleta"), y en "Amanecer", v. 11 ("realicé la tremenda conjetura" $\longrightarrow$ "resentí la tremenda conjetura" $\longrightarrow$ "reviví la tremenda conjetura"); o la simultánea (EF69) desaparición, en cinco textos, de sintagmas en los que el abstracto humillación se refiere a entes inanimados ("la humillación de las casas", "Barrio reconquistado", v. 8; "humilla las seniles butacas", "Sala vacía», v. 23; "casas / miedosas y humilladas", "Arrabal", vv. 5-6; "redime la calles humilladas", "Sábados", v. 7; "pobre cielo humillado", "Despedida», vv. 9-10).

Llaman la atención la sistematicidad y la sincronía de tales operaciones, pero en Borges lo primero no parece depender en absoluto de lo segundo. Enmiendas de este mismo tipo pueden ser llevadas a cabo, con la misma sistematicidad, en la diacronía de la revisión. Se trata, es más, de una de las características más sobresalientes de la reescritura borgeana: la labor de corrección se presenta fraccionada a lo largo del tiempo, pero las sustituciones elegidas presentan, pese a la longitud temporal del proceso de revisión, una coherencia fortísima ${ }^{5}$.

Copioso podría ser también el muestreo relativo a los otros dos tipos mencionados más arriba, tanto aquel en el que al abandono repetido de un mismo término corresponde una pluralidad de opciones sustitutivas, como aquel en el que, por el contrario, se repite la variante introducida. Sólo a título de ejemplo cito la supresión de copiar (L43) en dos contextos semejantes como "La vuelta", v. 6 ("he copiado andanzas de antaño" $\rightarrow$ "he repetido antiguos trayectos"), y "Alquimia", v. 19 ("copia los meandros" $\longrightarrow$ "sigue los meandros"); la de acallar (L43) en un sintagma sinestésico tanto en "La Recoleta", v. 28 ("se acalla el simulacro de los espejos" $\longrightarrow$ "caduca el simulacro de los espejos") como en "Atardeceres", v. 8 ("y acalla el barullero resplandor", suprimido); de brioso (E64) en "La noche de San Juan",

de 1934 a 1967), ES. (Elogio de la sombra, 1969), OT (El oro de los tigres, 1972), $R P$ (La rosa profunda, 1975), $M H$ (La moneda de hierro, 1976), HN (Historia de la noche, 1977), C (La cifra, 1981), Con (Los conjurados, 1985). Para FBA, LE y $C S M$ las referencias son a las primeras ediciones, para los otros textos sigo la edición $E 77$ (decimosexta reimpresión, de 1986).

${ }^{5}$ Cf. T. Scarano, "Per uno studio...". 
v. 7 ("briosa llamarada" $\longrightarrow$ " "alta llamarada") y en "Los llanos", v. $14(L E)$ ("briosa intensidad" $\rightarrow$ "larga intensidad"); la sustitución de advertir (E54) en "La vuelta», vv. 8-9 por el más neutro ver, y en la cercana "Resplandor», v. 13 por notar. A tales pérdidas se corresponde la aparición de términos nuevos destinados a gozar de una frecuencia significativa en la "futura", pero a menudo ya "coetánea" producción borgeana. En "Ausencia", v. 1 "vida inmensa" pasa a "vasta vida" en EF69, edición en la cual también "tiempo generoso e incierto" de "Caminata", v. 25, se modifica en "tiempo vasto y generoso". Del adjetivo vasto no hay ninguna constatación en $F B A, L E$ y CSM, y se presenta en la obra en verso sólo después de 1960 , registrando un total de unas 30 apariciones ${ }^{6}$; del mismo modo, magia y sus derivados aparecen sólo dos veces en las redacciones originales, mientras que su frecuencia en la producción sucesiva a 1940 es altísima, lo que permite explicar las modificaciones de «Amanecer", v. 32 "que logran en común alquimia las ánimas" $\rightarrow$ "que logran en compartida magia las almas" y "Despedida", v. 3 "el mar será una milemio entre nosotros" $\rightarrow$ "el mar será una magia entre nosotros".

En un plano de mayor significación se colocan algunos cambios que testimonian conexiones directas (aunque no inmediatamente visibles) entre enmiendas diversas y compensatorias.

Examinemos algunos fragmentos de «El truco"; la versión de S. reza:

6 y una risueña génesis va poblando el tiempo usurpado con los brillantes embelecos de una mitología criolla y tiránica.

...

17 Una gauchesca lentitud va refrenando las palabras que por declives patrios resbalan

22 los jugadores en fervor presente copian remotas bazas

${ }^{6}$ Los datos relativos a las frecuencias de aparición provienen de T. SCARANo y M. SASsi, Concordanze per lemma dell'opera in versi di J. L. Borges, M. Baroni, Viareggio, 1992. 
mientras, en cambio, el final es:

$$
\begin{aligned}
& \text { y una creación risueña } \\
& \text { va poblando el tiempo robado } \\
& \text { con las floridas travesuras } \\
& \text { de una mitología casera. } \\
& \ldots \\
& \text { Una lentitud cimarrona } \\
& \text { va demorando las palabras } \\
& \text {. . } \\
& \text { los jugadores de esta noche } \\
& \text { copian antiguas bazas. }
\end{aligned}
$$

Todas las variantes son de EF69, excepto las de los vv. 6 (que discutiré más adelante) y 17 , introducidas en $L 43$. De las correcciones de EF69, cuatro, las de lo versos 8, 19 (suprimido), 22 y 23 , están en relación con la coetánea revisión de textos muy próximos, y tres incluso con modificaciones de un único poema, "Calle desconocida». Veámoslo con más detalle.

El v. 8 pasa de "con los brillantes embelecos" a "con las floridas travesuras". Tanto embeleco como travesura son términos que pertenecen exclusivamente al léxico de la producción juvenil; la utilización de travesura en una época tan tardía constituye por lo tanto un caso bastante atípico y contradice una norma correctiva caracterizada en cambio por la intención de poner al día el léxico de las primeras recopilaciones poéticas. Sin embargo, una valoración atenta de las implicaciones intertextuales que orientan la sustitución, explica perfectamente esta variante; se trata en efecto de una modificación relacionada con la sustitución coetánea, en la cercana "Calle desconocida", v. 14, de "travesuras de columnitas y aldabas" por "modestas balaustradas y llamadores": la caída de travesura se ve compensada por su inmediata acogida en el v. 8 de «El truco».

También la supresión, en $E F 69$, del v. 19 “que por declives patrios resbalan" parece depender de un cambio que, en la misma edición, afecta a "Calle desconocida». Se trata de la corrección de los vv. 4-6 - de los que me ocuparé más a fondo en el tercer apartado- que pasan de:

y la venida de la noche se advierte

5 como una música esperada no como símbolo de nuestra primordial nadería 
y la venida de la noche se advierte

como una música

esperada y antigua

como un grato declive.

La nueva lección del v. 6 influirá sobre la resolución de suprimir el v. 19 de «El truco», en un cierto sentido duplicado de la misma imagen. También el cambio remoto $\longrightarrow$ antiguo en el v. 23, puede considerarse incluido en este conjunto de relaciones, porque reproduce la incorporación de antiguo en el v. 5 de "Calle desconocida". Por lo que se refiere por fin al cambio del v. 22, que pasa de "los jugadores en fervor presente" a "los jugadores de esta noche', los textos implicados son dos, y respecto a éstos la modificación de "El truco" - la explicitación de un deícticosirve por el contrario de imput. Se trata del v. 6 de "Final de año" que, una vez más en EF69, varía de "la altiplanicie de la medianoche serena" a "la altiplanicie de esta noche", y del v. 3 de "Un patio" que pasa de "La gran franqueza de la luna llena" a "Esta noche, la luna, el claro círculo".

Un examen de la relación espacial en la que se encuentran no sólo los textos conectados con las variantes de «El truco", sino también muchos de los que he extraído los ejemplos hasta aquí presentados, permite una constatación interesante: los fenómenos de repetición de las modificaciones, y los de implicación o compensación caracterizan de manera particularmente vistosa poesías cercanas unas a las otras. Las muestras aducibles son numerosas $^{7}$ y permiten articular una hipótesis sobre el método

7 Podemos señalar algunas relativas siempre al bloque de los primeros textos (que son, recordemos, "Las calles", "La Recoleta", "Calle desconocida", "El jardín botánico», "La Plaza San Martín", "El truco», "Final de año», "Un patio»). L43 sustituye por razones fónicas aún no en el v. 3 de "Calle desconocida" y en el v. 26 del contiguo «El jardín botánico»; un claro caso de compensación se registra después entre el v. 16 del primero ("se me adentró en el corazón anhelante", que $L 43$ transforma en "entró en mi vano corazón"), y el v. 5 del segundo (en el que "su vana lumbrerada de hojas" pierde en el mismo año vano apenas introducido en la poesía inmediatamente precedente y se convierte en 'su lumbre de hojas"). Condicionamientos se pueden rastrear además entre "Las calles" y "Calle desconocida" (la caída en el v. 13 de este último del adjetivo austero del sintagma "casas austeras" ha sido dictada por el v. 9 de "Las calles" que presenta "austeras casitas"); y entre "La Recoleta" y "La Plaza San Martín» (la modificación de EF69, en el v. 22 de este último, de "el puerto se abre a latitudes lejanas" a "el puerto anhela latitudes lejanas", está al menos sugerida por la revisión llevada a cabo, en el mismo 1969, de los vv. 18-19 de "La Recoleta", que pasan de "Equivocamos tal paz de vida con 
concreto aplicado por Borges en las revisiones. En primer lugar, la relación que el conjunto de las correcciones mantiene con la evolución editorial de $F B A$ - las revisiones afectan a casi todas las reediciones de la obra poética - sugiere por lo menos la sospecha de que aquéllas han sido consecuencia, mucho más que causa de éstas $^{8}$. En segundo lugar, la dinámica que puede reconstruirse sobre la base de las relaciones intertextuales entre las variantes induce a conjeturar que el trabajo de reescritura no ha afectado a los textos independientes en ciertos momentos dislocados en el tiempo, sino que ha sido llevado a cabo en un periodo determinado y presumiblemente bastante restringido. Considero, por lo tanto, que se puede hablar con toda propiedad de revisiones sistemáticas, que afectan al cuerpo completo de la recopilación, y, lo que es más, que han sido llevadas a cabo siguiendo el orden de las poesías. Muchos de los casos que me dispongo a tratar — más complejos que los que hasta ahora se han visto-, corroborarán, espero, esta hipótesis.

«Las calles», "Arrabal» y «Barrio reconquistado» presentan un interesante caso de condicionamiento recíproco. Los vv. 3-6 de «Las calles» aparecen así en $S$ :

No las calles enérgicas molestadas de prisas y ajetreos, sino la dulce calle de arrabal enternecida de árboles y ocasos

EF69 corrige:

el morir / y alabamos el sueño y la indiferencia" a "Equivocamos esa paz de vida con la muerte / y creemos anhelar nuestro fin / y anhelamos el sueño y la indiferencia"), etcétera.

${ }^{8}$ Las nuevas ediciones están claramente motivadas por la necesidad de integrar el corpus de la obra poética con los textos de nueva composición (las composiciones de Otros poemas hasta E62, después El otro, el mismo en E64, Para las seis cuerdas en E66, Elogio de la sombra en E69, etc.). Y la revisión de EF69, lejos de contradecir este dato, no hace más que confirmarlo; su valor se nos aparece, en efecto, totalmente congruente con la importancia de la iniciativa editorial a la que está unida, ya que no sólo inaugura, casi al mismo tiempo de Elogio de la sombra (ésta en agosto, Fervor en septiembre) la nueva colección de Emecé, titulada Obra poética de Borges (que de ahora en adelante acogerá todas las primeras ediciones de las nuevas recopilaciones poéticas), sino que constituye además, después de la princeps de 1923, la primera edición de esta recopilación en volumen suelto. 
No las ávidas calles, incómodas de turba y de ajetreo sino las calles desganadas del barrio casi invisibles de habituales, enternecidas de penumbra y de ocaso.

El impulso del cambio de "la dulce calle" por "las calles desganadas" se encuentra en la intención de construir una estructura de precisos paralelismos opositivos, congruente con la fuerza con la que se quiere expresar la diversidad de los dos tipos de calles, las del centro y las de la periferia; la sustitución del genérico dulce con desganado es consecuente con la de enérgicas con ávidas, y consigue oponer dos adjetivos semánticamente contrarios (lo que no sucedía en la lección de $S$ ) en una adversativa que articula como quiasmo los dos sintagmas. Pero el interés mayor de la operación consiste en la incorporación de "casi invisibles de habituales", verso que conecta con "Las calles" los pasajes de dos textos de $F B A$ y las correcciones a las que han sido sometidos. El primer caso se refiere a "Arrabal»: la connotación de apatía propia del término desganado introducido en el v. 5, en un contexto que contiene arrabal, es recogida por la nueva lección de los versos iniciales de este texto, que pasan, en EF69, de:

El arrabal es el reflejo de la fatiga del viandante

a:

El arrabal es el reflejo de nuestro tedio.

El segundo caso procede de "Barrio reconquistado» cuyos versos de apertura, retocados en el mismo 1969, permiten suponer un recorrido bidireccional hacia y desde "Las calles", la versión original:

Nadie justipreció la belleza

de los habituales caminos

puede haber constituido, a través de una conexión memorística, el impulso genético de ese "casi invisibles de habituales" (el tema de "Barrio reconsquistado» es el redescubrimiento, después de una tormenta, de la belleza de las calles de la periferia, que la costumbre ha convertido en imperceptible); y, por el contrario, el nuevo verso de "Las calles" puede ser el responsable de la modificación que reduce los dos versos al único 
Nadie vio la hermosura de las calles

suprimiendo habituales, repetitivo respecto al nuevo verso de «Las calles", e introduciendo vio, que me parece difícil suponer independiente de invisibles.

Como conclusión de esta primera parte, una variante de «La vueltas permite, además de discutir un caso ulterior de implicaciones intertextuales, avanzar otra hipótesis más, relativa a las modalidades del trabajo de revisión.

El verso inicial de "La vuelta" presenta tres versiones:

Después de muchos años de ausencia $S$

Al cabo de los años

Al cabo de los años del destierro.

EF69

El motivo central de este texto - de notable relieve en el contexto de $F B A$ - es autobiográfico: la vuelta del título es la del joven Borges a Buenos Aires después de siete años transcurridos en Europa, y el poema en su conjunto expresa de modo orgánico un tema que atraviesa numerosos textos de la recopilación, el del reencuentro con el espacio doméstico y urbano de la infancia, su reconocimiento, y su reapropiación. Todo $F B A$ puede leerse como una búsqueda, con la guía de señales fragmentarias y desenfocadas, de una realidad perdida que se quiere recuperar, pero al mismo tiempo como un proceso de conocimiento de lo nuevo, es decir, de todo lo que no encuentra confirmación en la memoria del Borges adolescente. Y es respecto a este ámbito de significados que asumen particular interés los avatares del primer verso. La caída de la especificación "de ausencia" se debe, creo, a la intención de evitar la rima asonante entre ausENCIA e infANCIA del segundo verso ("busqué la casa primordial de la infancia"). Esta radical decisión de suprimir el genitivo, con lo que se borra un elemento importante en la economía total del mensaje, es anulada por $E F 69$, que reconstruye el sintagma en su estructura originaria, utilizando sin embargo destierro, que satisface las motivaciones de la caída de ausencia. El interés del cambio reside en la distinta valoración que la elección de destierro expresa respecto al periodo de residencia europea. Se trata de un cambio radical de perspectiva: en la del Borges septuagenario el regreso a casa se presenta como el retorno a la patria de un exiliado. Es bien sabido que la adquisición de un sentimiento de argentinidad fue un proceso gradual y sucesivo al retorno a Argentina, y cómo a su 
maduración contribuyó en medida relevante precisamente ese acto de apropiación de la realidad argentina que subyace a las tres recopilaciones del decenio de los años veinte ${ }^{9}$. La corrección de EF69 tiene como telón de fondo este proceso, al que es paralela y complementaria una igualmente gradual reconsideración del valor del periodo europeo.

El contexto en el que hay que valorar la integración de EF69 está compuesto de al menos otras dos operaciones de corrección llevadas a cabo en otras poesías de la recopilación. El primero se halla en "Arrabal", texto que expresa de manera emblemática el proceso de apropiación del espacio urbano; la conclusión de $S$ era la siguiente:

\author{
y sentí Buenos Aires \\ y literaturicé en la hondura del alma \\ la viacrucis inmóvil \\ de la calle sufrida \\ en el caserío sosegado.
}

Este final, que Anita Barrenechea juzga "ineficaz"10, y que explicita las fases del proceso - revelación ("y sentí"), apropiación espiritual ("en la hondura del alma") y comunicación ("literaturicé') - , se transforma de manera radical en $L 43$ en algo distinto, estableciéndose una oposición entre experiencia argentina y experiencia europea; los cinco versos, reescritos, quedan así:

y sentí Buenos. Aires:

esta ciudad que yo creí mi pasado

es mi porvenir, mi presente;

los años que he vivido en Europa son ilusorios

yo he estado siempre (y estaré) en Buenos Aires.

Al reconocimiento de Buenos Aires como realidad presente y perteneciente a él, sigue como consecuencia una operación de desrealización de la experiencia europea. Nada de todo esto estaba en $S$. No es que la operación conlleve, para retomar la afirmación de Barrenechea, una mayor eficacia de la conclusión, sino que sim-

${ }^{9}$ Cf. Ramona Lagos, Jorge Luis Borges 1923-1980. Laberintos del espiritu, interjecciones del cuerpo, Barcelona, 1986, en particular los dos primeros capítulos de la primera parte.

10 A. Barrenechea, La expresión de la irrealidad en la obra de Borges, ed. aumentada, Buenos Aires, 1984 ( $1^{\text {a }}$ ed.: 1957), p. 14. 
plemente se confiere otro final al poema, el requerido por la perspectiva ulterior del Borges adulto que relee y reescribe una fase de su propia experiencia existencial y cultural. La segunda operación relacionada de alguna manera con la de "La vuelta" está constituida por la corrección de los versos finales de "Las calles" (otro texto en el que el proceso descrito se hace tema), que de:

Hacia los cuatro puntos cardinales se han desplegado como banderas las calles; ojalá en mis versos enhiestos vuelen esas banderas

pasan, en EF69, a:

Hacia el Oeste el Norte y el Sur se han desplegado - y son también la patria - las calles, ojalá en los versos que trazo estén esas banderas

corrección que logra enfatizar el tema de la patria, al precio, sin embargo, de la pérdida de un juego de analogías metafóricas sobriamente aludido.

Pero, como he adelantado, las modificaciones del primer verso de «La vuelta» presentan un interés especial, porque nos permiten conocer un segundo e importante dato relativo al modo en el que Borges llevó a cabo la revisión. La sucesión de ausencia $\longrightarrow$ $\phi \rightarrow$ del destierro sugiere, por lo menos, la hipótesis de que en la nueva lección de EF69 influye de manera determinante la vieja de $S$ : "del destierro" aparece, en efecto, como una variante presumiblemente mucho más condicionada por la redacción $S$ que por E66, que había eliminado el genitivo. La hipótesis es, en mi opinión, bastante sugestiva: la operación de reescritura más radical y extensa, la de EF69, podría haber tenido lugar en presencia del texto original. Borges, que en 1969 estaba ya totalmente ciego y se servía de intermediarios tanto para la escritura como para la lectura, podría haber elaborado EF69 acompañando la operación de revisión de $E 66$ con una relectura de esa suerte de incunable que para entonces era la edición Serrantes. Intentaré sostener tal hipótesis - que tanto aclara sobre la relación particularmente contradictoria que ha unido a Borges con estos primeros textosaduciendo a continuación algunos muestreos que me parecen especialmente convincentes. 
Bastante parecido a io sucedido con "La vuelta» es lo que ocurre en el v. 3 de «La Recoleta». En $S$ el verso rezaba: "irrealizados por tanta grave certidumbre de muerte"; coherentemente con la orientación correctiva responsable de la caída de numerosísimos adjetivos, L43 modifica " grave certidumbre" en "certidumbre", decisión reproducida más adelante en el v. 33 donde "grave horror" pasa, en la misma L43, a "horror". La lección de L43 se mantiene invariada hasta $E F 69$, que reescribe: "por tantas nobles certidumbres del polvo": lección nueva, sí, pero inequívocamente debida al graves de $S$. No hace falta abandonar este texto para encontrar otro caso. Los vv. 17-19 son sometidos nada menos que a cuatro revisiones, cuyos cambios se centran sobre todo en los dos verbos sobre los cuales se sostiene la construcción adversativa. Las fases de redacción son las siguientes:

$S \quad$ equivocamos tal paz de vida con el morir y mientras creemos anhelar el no ser lanzamos jaculatorias a la vida apacible

L43 equivocamos tal paz de vida con el morir y mientras creemos alabar el no-ser alabamos el sueño y la negligencia

E58 como L43 con único cambio: indiferencia en vez de negligencia

E64 equivocamos tal paz de vida con el morir y alabamos el sueño y la indiferencia...

EF69 Equivocamos esa paz con la muerte y creemos anhelar nuestro fin y anhelamos el sueño y la indiferencia.

El interés de este ejemplo no consiste sólo en el hecho de que EF69 recupere un verso (y una estructura lógico-sintáctica) del que E66 no conserva huella, sino sobre todo en el hecho de que anhelar, el verbo que al final resuelve el paralelismo entre las dos frases coordinadas, pertenece sólo a la redacción de $S$, y de ésta, me parece indudable, proviene. No requieren ningún comentario los casos de "Jardín", v. 2 y de "Sábados", v. 34: "sierras ásperas", de la primera pasa en $L 43$ a "sierras áridas", y se mantiene hasta la revisión del 1969 que repristina "sierras ásperas"; "soy tan sólo un anhelo" de la segunda se convierte en "soy tan sólo un deseo", en 1943 para recuperar en 1969 la forma originaria "soy tan sólo 
un anhelo". En «Benarés», v. 35 “que mientras brujuleo las imágenes" pasa en $L 43$ a "que mientras juego con inciertas metáforas" para consolidarse en EF69 en la lección "que mientras juego con dudosas imágenes", en la que dudosas reescribe inciertas, y metáforas cede frente al viejo imágenes. Y la ejemplificación podría enriquecerse, y extenderse incluso a $L E$ y $C S M$.

Se podría objetar que se trata de simples coincidencias que no prueban inequívocamente nada; se podrían incluso citar dos o tres (pero no más) pasajes en los que el texto de $S$ queda restablecido por revisiones diversas de la de 1969; considero con todo que no se pueden alimentar dudas razonables acerca del hecho de que una relectura de $S$ ha tenido lugar en el curso de la corrección de EF69. Y la certeza proviene de casos más clamorosos y convincentes que los hasta ahora citados, casos en los que no se verifican simplemente vueltas atrás de las lecciones, sino cambios determinados por implicaciones entre la redacción anterior a EF69 y la de $S$. Presento a continuación un par de ellos.

El primero es el fragmento conclusivo de "Arrabal», al que, por otra razón, me he referido más arriba; el texto de $S$ es:

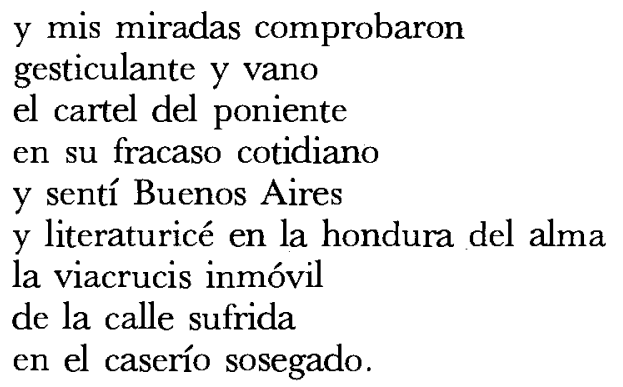

En EF69 estos versos se leen así:

y divisé en la hondura

los naipes de colores del poniente y sentí Buenos Aires.

Esta ciudad que yo creí mi pasado es mi porvenir, mi presente; los años que he vivido en Europa son ilusorios, yo estaba siempre (y estaré) en Buenos Aires.

Si entre estas dos redacciones no se hubieran registrado lecciones intermedias, nadie tendría dificultades en reconocer un caso de compensación entre la caída del verso "y literaturicé 
en la hondura del alma" y la recuperación del término hondura en el verso de nuevo cuño "y divisé en la hondura" que reescribe "y mis miradas comprobaron". Pero no es así: entre la primera lección y la última citada se encuentra la establecida por L43 (que es la lección sobre la que interviene EF69), y en ésta, que mantiene inmutados los primeros cinco versos del fragmento, el verso del que debería provenir hondura no puede leerse, porque ha sido sustituido - como se ha visto ya - por "esta ciudad que yo creí mi pasado'.

El segundo caso es, tal vez, incluso más clamoroso y, al mismo tiempo, está más escondido. Se trata de una modificación que afecta al v. 12 de "Benarés". El fragmento en $S$ :

El sol salvaje

$$
\text { ... ha de estrujar los muros }
$$

de colores borrachos

EF69 corrige:

$$
\begin{aligned}
& \text { El brusco sol } \\
& \text {.. escalará los muros. }
\end{aligned}
$$

La variante que nos interesa es la adquisición de escalar en vez de estrujar. Este último verbo había caído ya en "La guitarra», v. 31 , durante la revisión de $L 43$, y escalar se halla en una expresión, parecida a la de «Benarés» en "Apuntamiento de Dakar", v. 15, de Luna de enfrente ("el sol como un ladrón escala los muros"). Se podría suponer que el escalar de «Benarés» documenta una recuperación de la composición de 1925; sin embargo, me parece más convincente una conjetura más fácil: que la fuente de esa imagen se halle ya en $F B A$. En «Ciudad", poema antecedente de «Benarés», si bien en posición no inmediatamente anterior. Los versos que nos interesan son:

Colores impetuosos escalan las atónitas fachadas

evocados de forma verosímil también por la cercanía de los sintagmas "colores impetuosos" y "colores borrachos". No habría nada particularmente interesante en todo esto, si no fuera por el detalle de que "Ciudad" no forma parte de Fervor de 'Buenos 'Aires desde $L 43$, y por lo tanto se halla presente exclusivamente en $S$. 
Si es plausible un lazo entre los dos fragmentos, éste constituye una prueba ulterior en apoyo de la presencia de $S$ durante la revisión de $E F 69$, y constituye también el primer ejemplo del fenómeno del que me dispongo a hablar, el de los condicionamientos de la reescritura por parte de la relectura.

\section{De la Relectura a la REESGRITURA}

El cambio del ya citado verso $6 \mathrm{de}$ «El truco", "una risueña génesis" - $\longrightarrow$ "y una creación risueña", ejemplifica un tipo particular de interferencia capaz de explicar modificaciones no justificables ni por razones de analogía con otras llevadas a cabo, ni por razones de compensación en el interior del sistema de modificaciones, ni tampoco por la coetánea actividad de escritura.

En los casos que siguen, la relación entre la lección cambiada y otros pasajes del conjunto sometido a revisión se presenta de forma más escondida; dichos pasajes parecen constituir en efecto, sea por no haber recibido correcciones, sea porque la remanipulación afecta sólo a una parte, elementos más contrarios que favorables a la hipótesis de conexión que estamos sosteniendo. Y sin embargo, estos vínculos constituyen de hecho, en la compleja dinámica que caracteriza el proceso correctivo, formas, por muy particulares que sean, de implicaciones. Si se tiene debidamente en cuenta que la praxis de revisión comporta, por su misma naturaleza, una actitud constantemente interrogativa, en la cual el rechazo y la confirmación poseen el mismo grado de potencialidad, no puede subestimarse la eventualidad de que, además de modificaciones dependientes de $-o$ determinantes de- otras modificaciones, el proceso de revisión presente también correcciones dependientes de $-o$ determinantes de (pero estos son casos evidentemente no comprobables) - reconfirmaciones llevadas a cabo en el momento de la relectura. Tal posibilidad se realiza obviamente con más frecuencia en el caso de revisiones en las cuales la operación correctiva se presenta de manera particularmente vistosa, ya que en éstas la elección conservadora constituye una respuesta a la relectura no menos "fuerte" que la elección innovativa, y por tanto con una incidencia no menor en el interior de la red de relaciones que conectan las correcciones entre sí y con elementos del macrotexto.

La modificación génesis $\longrightarrow$ creación se debe, creo, a la intención de evitar una segunda aparición del término, casi al lado del 
v. 25 de «El jardín botánico»: "que hubo Dios de sentir antes del génesis", en el cual Borges acaba de intervenir, corrigiendo "que sintió Dios antes del génesis". Como se puede ver, el retoque no afecta de modo particular al término génesis; sin embargo el hecho mismo de que ese verso haya sido objeto de revisión, convierte en activos sus componentes dentro del sistema al que la variante pertenece. Dicho de otra manera, durante la corrección de L43, Borges se ve obligado a tomar en consideración, a breve distancia uno del otro (en $S$ «El jardín botánico» precede por dos textos "El truco") dos versos en los cuales aparece, puesto además de relieve al final de verso, el mismo término génesis. De ahí el impulso de la corrección.

De la misma naturaleza es la lógica contextual que se halla en la base del paso, en "Atardeceres", v. 21, de "rezó un Avemaría de colores" a "fue unos vanos colores". La modificación está conectada, me parece, con las que afectan, en el ámbito de la misma revisión (L43), a dos casos de poemas antecedentes: «Benarés”, vv. 30-31, "la voz del almuédano / que ya rezó el disperso rosario de los astros" y "La noche de San Juan», vv. 12-13 y "la soledad rezando / el disperso rosario de los astros". De las tres imágenes, la revisión de $L 43$ conserva sólo la del texto intermedio: cae todo el v. 31 de "Benarés", se modifica el de "Atardeceres». En mi opinión, el responsable de ambas modificaciones es "La noche de San Juan", es decir, el único caso en el que la imagen se mantiene. La hipótesis puede parecer algo azarosa en lo que se refiere a "Benarés", poema que precede a "La noche de San Juan", pero me parece incluso obvia para el caso de "Atardeceres»: la variante es consecuente de la relectura y de la reconfirmación del final de "La noche de San Juan".

Más sencillo es el proceso que ejemplifica el v. 13 de «Calle desconocida»: "Todo - honesta medianía de las casas austeras", que Borges corrige, en EF69, como "Todo - la medianía de las casas" para evitar la repetición de un sintagma ya presente en el anterior "Las calles", que en el v. 9 había mantenido "donde austeras casitas apenas se aventuran'”. Parecido a éste es el caso del verso 11 de «Jactancia de quietud" $(L E)$, "El tiempo está viviéndome", no retocado jamás, y a cuya relectura hay que imputar con buena probabilidad la supresión (en E64) del casi idéntico "El tiempo irá viviéndome" de "Para una calle del oeste", v. 6 $(L E)$.

Se pueden citar otros dos cambios que afectan a «Sábados». La supresión en E64 del v. 32, "se desangra el silencio", se debe 
tal vez a la relectura de un verso de "La noche de San Juan", poema revisado también en 1964, y que conserva, en el v. 7 "se desangra en alta [antes briosa] llamarada"; la supresión del verso inicial de la cuarta estrofa, "Suave como una rosa fue tu silencio", llevada a cabo en $L 43$, se debe con bastante probabilidad al hecho de que éste repite por tercera vez una imagen ya presente de forma bastante similar en otros dos versos de otras tantas poesías inmediatamente precedentes: "Suave como un sauzal está la noche", v. 3 de «La noche de San Juan» y "olorosa como un mate curado la noche", v. 1 de «Caminata", textos ambos sometidos a revisión en $1943^{11}$.

Hasta aquí todos los casos tratados ejemplifican consecuencias de tipo demoledor: el efecto de la relectura sobre el proceso de revisión consiste en el abandono (por sustitución o por supresión) de la vieja lección. Una variante de E72 en "La Chacarita" de CSM permite completar el cuadro presentando un caso de condicionamiento por parte de la relectura sobre la elección de la lección de nuevo cuño. El v. 25 pasa de "y convencido de corruptibilidad el suburbio" a. "y convencidas de mortalidad las orillas', con un uso tardío de orilla con el significado de periferia. Una decisión que contrasta con la eliminación general de los argentinismos puesta en marcha a lo largo del proceso de las revisiones, y que en mi opinión puede provenir sólo de la relectura de dos textos, ambos revisados en E72. Los pasajes en cuestión pertenecen a "Versos de catorce» (vv. 9 y 21-22, LE): "y supe en las orillas, del querer de una novia" (transformado en "y supe en las orillas, del querer, que es de todos") y "Yo presentí la entraña de la voz las orillas / palabra que en la tierra pone lo audaz del agua"' (en E72: "el azar del agua"'), y a "Elegía de los portones", vv. 53-54 (CSM): "y el cielo amanzanado de tus orillas guarda / paz mejor que el del campo".

Las correcciones que afectan, en $E F 69$, a los dos versos finales de "El truco" inducen a formular, si bien con las debidas

${ }^{11}$ Especular, pero invertida, es la continuación de la historia de este último verso: fue vuelto a utilizar, con una ligera variación, en $L E$ como verso inicial de "En villa Alvear", "la noche es olorosa como un mate curado / y es vagancia en las calles y aventura en los pechos", pero cuando $L 43$ suprime esta poesía, entra en "Versos de catorce" (v. 16) bajo la forma de variante de los versos "y apunté la patriada que hacen los organitos / acriollando gorriones a puro moler de tangos", que se convierten en: "y el destino que acecha, tácito en el cuchillo, / y la noche olorosa como un mate curado". 
reservas, como es obvio, una hipótesis lo suficientemente sugestiva como para detenernos algo más en ella. La nueva lección es:

hecho que resucita un poco, muy poco

a las generaciones de los mayores

que legaron al tiempo de Buenos Aires

los mismos versos y las mismas diabluras.

La lección (de L43) revisada es:

Hecho que inmortaliza un poco, apenas,

a los compañeros muertos que callan.

Como es bien sabido, la bibliografía borgeana registra otro texto titulado "El truco". Se trata de un fragmento de Evaristo Carriego (1930) que forma parte de las Páginas complementarias del capitulo cuarto. Este escrito fue publicado, con anterioridad, en las columnas del diario bonaerense La Prensa el 10 de enero de 1928, y sucesivamente, como segundo ensayo de $E l$ idioma de los argentinos editado en el mismo año. Entre el poema de $F B A$ y el texto en prosa existen numerosas y precisas correspondencias que autorizan a considerar al ensayo como una prosificación de la poesía. A título de mero ejemplo citamos algunos fragmentos del texto de Evaristo Carriego indicando entre corchetes el número del verso al que hacen referencia:

Cuarenta naipes quieren desplazar la vida [cf. v. 1]... un as de espadas que será omnipotente como don Manuel [cf. vv. 14-15]... Cuarenta naipes - amuletos de cartón pintado, mitología barata, exorcismos- les bastan para conjurar el vivir común [cf. vv. 1, 2, $3 ; 11]$... La pública y urgente realidad en que estamos todos, linda con su reunión y no pasa; el recinto de su mesa es otro país. Lo pueblan el envido y el quiero... el 7 de oros tintineando esperanza [cf. vv. 4, 10-13, 17] . . Todo jugador, en verdad, no hace ya más que reincidir en bazas remotas [cf. vv. 22-23 $]^{12}$.

12 Cito de El idioma de los argentinos, Gleizer, Buenos Aires, 1928, pp. 2934. Los versos a los que se reenvía son: "Cuarenta naipes han desplazado la vida" (v. 1); "la fuerza del as de espadas / como don Manuel, omnipotente" (vv. 14-15); "Amuletos de cartón pintado / conjuran en placentero exorcismo /.../ el vivir común se detiene", "la maciza realidad primordial", "Adentro hay otro país / las aventuras del envido y del quiero /.../ y el siete de oros tintineando esperanza" (vv. 4, 10-13, 17); "los jugadores en fervor pre- 
Se trata, como se puede apreciar, de un cotejo que demuestra ampliamente el estrecho parentezco de los dos textos. Manuel Ferrer lo trae a colación como apoyo a su propuesta de retrotraer la fecha del ensayo de La Prensa, que considera compuesto antes de 1923 (fecha de publicación de $F B A$ ) y contemporáneo al texto poético, en su opinión, "quintaesencia del libro. Los naipes del tahúr, que no llegó a corporeizarse"'13. El tema específico de estas páginas no me permite demorarme en un problema ajeno a ellas; encuentro con todo bastante singular, amén de contradictorio respecto a las costumbres de Borges, la decisión de mantener inédito durante cinco años un texto por el que demuestra un afecto especial, dado que lo rescata, al incluirlo en Evaristo Carriego, del olvido al que condena por el contrario todo el resto del volumen El idioma de los argentinos. Habría que preguntarse, además, cómo es que Borges no lo introdujo en Inquisiciones (1925) donde sin embargo acogió el fragmento "Buenos Aires", presentado declaradamente como resumen de la recopilación poética $F B A$. El ensayo parece además una profundización y una explicitación de las reflexiones metafísicas a las que el juego del truco puede servir de arranque. Estén como estén las cosas, parece precisamente el texto de Evaristo Carriego el responsable de la integración que en 1969 afecta al final del poema. No puede tratarse de una casualidad, en efecto, que los versos añadidos y la importante sustitución de inmortaliza por resucita hallen precisamente en el ensayo de cuarenta años antes su correspondencia precisa. Destaco en cursiva los elementos del texto en los que parece hallarse el origen de las variaciones:

Generaciones ya invisibles de criollos están como enterrados vivos en él: son él podemos afirmar sin metáfora (p. 34).

El diálogo se entusiasma hasta el verso, más de una vez. El truco sabe... versos para la exultación (p. 30).

Es un mundo ... inventado al fin por hechiceros de corralón y brujos de barrio... inventivo y diabólico en su ambición (p. 33).

La hipótesis de que las correcciones hayan sido precedidas por una relectura del texto en prosa puede parecer excesivamente

sente / copian remotas bazas" (vv. 22-23).

${ }^{13}$ Cf. Manuel Ferrer, Borges y la nada, Tamesis Books, London, 1971, p. 17 . 
dificil y artificiosa. La considero sin embargo plausible, porque, además de basarse en la evidencia del cotejo, responde plenamente a las peculiares características de la revisión de 1969 , la cual no se distingue solamente por la cantidad y por la calidad de las modificaciones, sino también por una labor de control general de la trayectoria textual de conjunto de $F B A$. Como he intentado documentar, toda una serie de variantes de $E F 69$ atestigua que Borges efectuó las correcciones teniendo presente la edición Serrantes, como para querer valorar, no ya sólo la lección con la que cada texto particular se presentaba, sino también las fases extremas de su metamorfosis. Como sabemos la operación estuvo lejos de ser meramente restaurativa, y sin embargo la decisión de corregir las versiones ya varias veces modificadas, recuperando en la lectura la lección por así decirlo auténtica, prueba que Borges asumió una actitud de verificación respecto a la cual no se puede excluir que, al proceder a la corrección de "El truco", solicitara que le fuera releído el antiguo texto en prosa.

\section{De la ESCRitura A LA REESCRITURA, y VUELTA ATRÁS}

Al tratar, en el primer apartado, de las causas de la supresión del v. 19 de "El truco" ("que por declives patrios resbalan"), adelanté la hipótesis de que pudieran rastrearse en las modificaciones aportadas por EF69 a los vv. 4-6 de "Calle desconocida". Ha llegado el momento de añadir algo más en torno a estos versos nuevos, cuyo origen debe reconocerse - en mi opinión - en un sistema de imágenes que se fue formando en un grupo de textos redactados en años cercanos a la introducción de la variante. Releamos los versos de "Calle desconocida" en la lección original y en la final:

y la venida de la noche se advierte

5 antes como advenimiento de música esperada

que como enorme símbolo de nuestra primordial nadería

y la venida de la noche se advierte

como una música esperada y antigua,

como un grato declive

y comparémoslos con los siguientes pasajes tomados de textos de El otro, el mismo y Elogio de la sombra: 
sombra que olvida, atareados espejos que multiplican, declives de la música, la más dócil de las formas del tiempo ("Mateo XXV, 30», vv. 12-13).

Por los íntimos dones que no enumero por la música, misteriosa forma del tiempo ("Otro poema de los dones", vv. 79-80).

El segundo crepúsculo.

Ese otro hábito del tiempo, la noche («Heráclito», vv. 8-9).

Por los vastos declives de la noche que lindan con la aurora, buscamos (lo recuerdo aún) las palabras de la luna... («Invocación a Joyce», vv. 5-8).

Esta penumbra es lenta y no duele; fluye por un manso declive y se parece a la eternidad («Elogio de la sombra», vv. 17-19).

La claridad de los fragmentos me exime de ulteriores comentarios. Se trata de un verdadero coágulo semántico, de una red que conecta con los motivos de la música y de la noche (incluyendo la metafórica de la ceguera) el tema del tiempo, y con los tres, la imagen del declive. La comparación noche $=$ declive introducida en la nueva lección repite la imagen metafórica de "Invocación a Joyce" ("declives de la noche"), pero es asimismo una cita, a través de la analogía noche = música de los vv. 4-5, de los "declives de la música" de "Mateo XXV, 30"; el "grato declive" es un sintagma semántica y fonéticamente muy cercano al "manso declive" de "Elogio de las sombra". En fin, la incorporación de antiguo referido a música traduce la conexión, recurrente en los pasajes citados, entre noche, música, y tema del tiempo. Las variaciones del fragmento examinado son, por lo tanto, activas por un lado, en cuanto determinan una modificación en «El truco» (recuerdo entre paréntesis que "El truco" se sitúa dos textos después de "Calle desconocida»), y pasivas por otro, es decir, condicionadas por poemas redactados en épocas más o menos cercanas a la de la revisión. 
Una dinámica muy similar a ésta es la que presenta un fragmento de "La Recoleta». EF69 corrige los vv. 4-5, que en $S$ eran:

nos demoramos en las veredas que apartan los panteones enfilados

y que ahora quedan de la siguiente manera:

nos demoramos y bajamos la voz entre las lentas filas de panteones.

La corrección halla una precisa referencia en el coetáneo cambio del v. 41 de "Benarés" que sustituye "con arrabales y cuarteles" por "con hospitales y cuarteles / y lentas alamedas", y me parece indudable que la nueva lección cita la de "La Recoleta». Pero tal vez ambas, y en modo especial esta última, recuerden algunos versos del "Poema de los dones" (vv. 29-32, $H$ ):

$\mathrm{Al}$ errar por las lentas galerías suelo sentir con vago horror sagrado que soy el otro, el muerto, que habrá dado los mismos pasos en los mismos días.

Pero también en este caso podemos remitirnos a todo un sistema:

Ya no compartirás la clara luna ni los lentos jardines («1964», vv. 2-3, OM).

Las lentas hajas vuelve un niño y grave sueña con vagas cosas que no sabe ("Lectores", vv. 13-14, OM).

Lento en la lenta sombra labrarías metáforas de espadas en los mares («A un poeta sajón», vv. 5-6, OM $)^{14}$.

${ }^{14}$ Del mismo parecer es Michel LAFon en su importante ensayo Borges ou la réécriture, Seuil, Paris, 1991: "la prosification qui du poème initial conduisit au texte en prose se trouve complétée par une versification - certes fort partielle- conduisant du texte en prose à la version (presque) finale du poème", p. 186. 
Un sistema que continúa activo después de 1969, y produce el "lento diccionario" de "A Islandia", v. 21 (OT) y "las lentas gradas" de «Susana Bombal», v. $8(O T)$.

Pero veamos un caso más rico, como es el de «Final de año", en el que la influencia de la escritura en la reescritura conlleva un articulado conjunto de sustituciones. En la lección de $S$ el texto es el siguiente:

Ni la minucia guarismal de reemplazar un tres por un dos ni esa metáfora baldía que convoca un año agonizante y otro que surge ni el cumplimiento de un enrevesado plazo astronómico

5 socavan con cataclismos de badajados y gritos la altiplanicie de la media noche serena y en agorería fantástica nos hacen aguardar las doce campanadas oscuras.

La causa verdadera

10 es la sospecha universal y borrosa

de las metafísicas posibilidades del Tiempo, es el azoramiento ante el milagro de que a despecho de alternativas tan infinitas pueda persistir algo en nosotros

15 inmóvil.

La operación más vistosa afecta en 1969 a los versos 9-15, o sea a la última frase de las dos de las que el poema se compone. El fragmento se presentaba, en el momento de la revisión, de la siguiente forma, resultado de los sucesivos cambios de $L 43, E 54$, E58:
La causa verdadera
es la sospecha universal y borrosa
del enigma del Tiempo;
es el asombro ante el milagro
de que a despecho de azares infinitos perdure algo en nosotros:
inmóvil.

Las correcciones de EF69 son mínimas: "universal y borrosa" pasa a "general y borrosa", " azares infinitos" a "infinitos azares"; pero tres versos añadidos (dos tras el verso $13 \mathrm{y} \cdot \mathrm{uno}$ como conclusión) modifican vistosamente el final de la poesía que se convierte en: 
de que a despecho de infinitos azares, de que a despecho de que somos

las gotas del río de Heráclito perdure algo en nosotros: inmóvil, algo que no encontró lo que buscaba.

Las modificaciones aparecen anómalas respecto a la costumbre, casi nunca contradicha, de reducir las estructuras morfosintácticas acumulativas; pero más sorprendentes aún aparecen el lenguaje y el sentido de las integraciones. Intentaremos descubrir a qué instancias responden, comenzando por los primeros dos versos nuevos, cuya fuente me parece un grupo de textos compuestos en los años sesenta y particularmente coherentes entre sí. Los primeros entre todos son "El reloj de arena" y "Arte poética" $(H)$. Este último es tal vez el texto en el que de forma más explícita Borges pone en relación la temática del tiempo con la palabra poética, cuya función es la de captar la sustancial identidad entre el continuo fluir en apariencia dominado por el azar y caracterizado por la multiplicidad y por la fugacidad de las cosas, y la permanencia eterna de éstas en una trama que garantiza su unidad. Incontenible mutación e inmutable permanencia son los dos opuestos que enigmáticamente el tiempo armoniza. "Final de año» es quizás el primer texto en el que, aún en embrión, se nos comunica el estupor cognoscitivo de tal intuición. No nos debe por lo tanto sorprender el hecho de que, aunque transformado tras la redacción de los textos mencionados, resuma imágenes y conceptos de todo ello.

La imagen del río como símbolo del tiempo y la referencia a Heráclito y a su pánta rhêi, aparecen por vez primera en «El reloj de arena", vv. 3-4 $(H)$ ("el agua de aquel río / en que Heráclito vio núestra locura"), después en la conocidísima "Arte poética» (baste pensar en los cuartetos inicial y final) y en "A quien está leyéndome», vv. 3-6 (OM, 1966) (“`No es acaso / tu irreversible tiempo el de aquel río / en cuyo espejo Heráclito vio el símbolo / de su fugacidad?'"). En los veinte años sucesivos a este texto, aparecerán una decena de referencias más al filósofo griego; y a muchas más numerosas apariciones estará destinado el río, símbolo del fluir del tiempo y de la vida (alrededor de veinte veces entre "El reloj de arena» y la fecha de las correcciones de las que nos ocupamos, y otras tantas en el resto de la producción). Es por lo tanto en el decenio 1959-1969 cuando queda definido el sistema 
de imágenes que servirá de output a "Final de año»; y es interesante observar su estructura en una decena de textos, desde "A un poeta menor de la antología» hasta "Heráclito" y "Rubaiyat» ${ }^{15}$.

Relacionado plausiblemente con la introducción de nuevos versos puede considerarse también el cambio del v. 8 de "nos hacen aguardar las doce campanadas oscuras" a "y nos obligan a esperar las doce irreparables campanadas'. Irreparables supone en efecto, en la misma dirección de aquéllos, una enfatización del carácter fatalmente irreversible del transcurrir temporal. Ahora bien, no parece irrelevante el hecho de que la marca de la irreparabilidad, propia del proceder incontenible del tiempo, de la vida y de la historia, se exprese con los afines irreversible, irrevocable, interminable en algunos de los textos que forman el sistema señalado: me refiero en concreto a "El reloj de arena" ("el curso irrevocable / del agua que prosigue su camino", vv. 7-8), "A quien está leyéndome" (" ¿No es acaso / tu irreversible tiempo el de aquel río", vv. 3-4), "Arte poética» ("Heráclito inconstante, que es el mismo / y es otro, como el río interminable", vv. 27-28), "Poema del cuarto elemento" ("el tiempo irreversible que nos hiere y que

${ }^{15}$ Un primer lejano precedente se halla en "A un poeta menor de la antología" (OM, 1954) ("el río numerable de los años", v. 4), siguen después "Elvira de Alvear" $(H)$ ("el errante río del tiempo / río y laberinto", vv. 1617), "Oda compuesta en 1960" $(H)$ ("El claro azar o las secretas leyes / que rigen este sueño, mi destino, / quieren... / que yo, la gota, hable contigo, el río, / que yo, el instante, hable contigo, el tiempo", vv. 1-7), "París 1856" $(O M, 1966)$ ("Enrique Heine piensa en aquel río, / el tiempo, que lo aleja lentamente", vv. 5-6), "Al vino" (OM, 1966) ("Junto a aquel otro río de noches y de días / corre el tuyo que aclaman amigos y alegrías", vv. 7-8), "Soneto del vino" (OM, 1966) ("El vino / fluye rojo a lo largo de las generaciones / como el río del tiempo", vv. 5-7), "Heráclito" (ES, 1968) "“Qué trama es ésta / del será, del es y del fue? / ¿Qué río es éste / por el cual corre el Ganges? / . . / El río me arrebata y soy ese río" vv. 14-23), "James Joyce” (ES) ("Dios prefijó los días y agonías / hasta aquel otro en que el ubicuo río / del tiempo terrenal torne a su fuente", vv. 4-6), "Rubaiyat" (ES) ("Torne a afirmar que el fuego es la ceniza / la carne el polvo, el río la huidiza / imagen de tu vida y de mi vida / que lentamente se nos va de prisa.", vv. 5-8). Con este mismo sistema, así como con los versos de "Final de año" examinados, hay que relacionar la corrección, también de EF69, de los vv. 14-15 de «Benarés", que de "y [el sol ha de] colgar de los hombros escurridizos / mochilas de calor" pasan a "y lel sol] resplandecerá en un río sagrado", recuerdo cierto de lós versos citados del reciente "Heráclito" y tạl vez también del más lejano «Poema del cuarto elemento" $(O M, 1944)$ : “y tu fuga se llama el Éufrates o el Ganges. / (Afirman que es sagrada el agua del postrero)", vv. 24-25. 
huye", v. 15), y además en la prosa poética «Mayo 20, 1928» ("para que el porvenir sea tan irrevocable como el pasado"). Pero los confines de la red se extienden aún más; utilizado por vez primera - al menos en poesía- en la corrección de 1969 del v. 8 de «Final de año», irreparable volverá a connotar el tema del tiempo en "Elegía», v. $6(C)$ : "el río irreparable de los años", verso que retoma el antiguo "río numerable de los años" de «A un poeta menor de la antología» ya recordado.

Conectada, a través de dos de los textos citados, con el sistema descrito, se nos aparece, si no la motivación, debida a razones de orden fónico, sí la decisión de sustituir plazo astronómico por proceso astronómico. Los vv. 2-4 eran, en la lección de L43:

ni esa metáfora baldía

que convoca un año agonizante y otro que surge

ni el cumplimiento de un intrincado plazo astronómico

EF69 corrige "año agonizante" en "lapso que muere" y "plazo" en "proceso". La primera de las dos correcciones encuentra, creo, su razón de ser en la mayor coherencia del genérico lapso con lo expresado en el verso de apertura (convertido en $L 43$ en " $\mathrm{Ni}$ el pormenor simbólico / de reemplazar un tres por un dos'), concepto que reduce a detalle precisamente la operación de computar el tiempo en medidas precisas. La segunda es sin duda una consecuencia de la primera: lapso impone la sustitución de plazo que traspone como anagrama sus fonemas. Pero la elección del sustituto proceso (desarrollo de las fases sucesivas de un fenómeno) no es casual: tanto en "Heráclito" como en "Rubaiyat", Borges se había interrogado en efecto sobre la naturaleza y el sentido de la trama que el proceso temporal determina: "¿Qué trama es ésta / del será, del es y del fue? / ¿Qué río es éste / por el cual corre el Ganges?"' (vv. 14-17).

Es éste el sentido también de un fragmento del más reciente “1982" (Con), en el que se lee (segundo párrafo): "Es una parte ínfima de la trama que llamamos la historia universal o el proceso cósmico".

Y llegamos, para concluir con «Final de año», al añadido, en 1977, del verso conclusivo "algo que no encontró lo que buscaba'. El verso, una suerte de glosa de todo el discurso, introduce el concepto de fracaso, expresado a través de la oposición buscar/encontrar. El "ruido" se hace más evidente si se considera que el verso añadido rompe la coherencia temporal del texto - ente- 
ramente en presente- metiendo en campo dos pasados. La perspectiva de la que provienen estos dos verbos no es la que sostienen los presentes. El final del año del que se habla es el de 1922; Borges es un joven de poco más de veinte años; el verso final tiene todo el aspecto de un balance conclusivo del Borges casi octogenario.

Contaminaciones del presente al que se refieren los textos de $F B A$, por parte de un "futuro" ya pasado, no son raras en la historia de la reescritura borgeana. A la ya comentada conclusión de Arrabal, se pueden añadir otros casos. Por ejemplo la significativa modificación (EF69) del v. 4 de "Benarés", que de "que mis pisadas no conocen', verso completamente inserto en el tema, muy recurrente en la poesía de los años veinte, de la vagancia, pasa a "que no han visto mis ojos", más adherente al tema de la ceguera; o (cercanísimos al sentido del verso conclusivo de «Final de año»), los versos de nuevo cuño "Campos de mi camino, firmamento / que estoy viendo y perdiendo", que en EF69 sustituyen en "Despedida" los originarios "Campos desalentados, pobre cielo / humillado en la hondura de los charcos / como ángel caído" (vv. 9-11); o por último la reescritura en E72 de "y canté la morosa gustación de esa gloria" como "y canté la aceptada costumbre de estar solo" (vv. 9-10).

Otra interesante muestra de un conjunto de implicaciones está formada por dos segmentos de "La Recoleta". Veamos el primero, los vv. 10-11 pasan de:

Hermosa es la serena decisión de las tumbas, su arquitectura sin rodeos

a:

Hermosa es la serenidad de las tumbas, la conjunción del mármol y de la flor

en $L 43$, y en EF69 a:

Bellos son los sepulcros, el desnudo latín y las trabadas fechas fatales, la conjunción del mármol y de la flor.

Las modificaciones del v. 10 responden a un intento de concisión y de síntesis expresiva; más compleja es por el contrario la cuestión que afecta a las dos variantes del v. 11. La génesis de la lección de $L 43$ se halla, en mi opinión, en el sistema de recí- 
procas conexiones que afectan al texto de Fervor y a las dos composiciones "Muertes de Buenos Aires" ("La Chacarita» y "La Recoleta") de CSM. Si el primero de éstos, por poner sólo un ejemplo, es una cita del incipit del texto de 1923 "convencidos de caducidad" variándolo apenas en "convencido de corruptibilidad" (v. 25, más tarde "Convencidas de mortalidad"), y recoge "caducidad" (término cuya aparición no se registra más que en estos dos casos) en el v. 56: "he oído tu palabra de caducidad y en ella no creo", la lección de $L 43$ del v. 11 atestigua un recorrido en dirección opuesta, de influencia por parte de "La Recoleta" de CSM sobre la de FBA. La variante en efecto cita la relación entre muerte y flor, originaria de la composición de CSM:

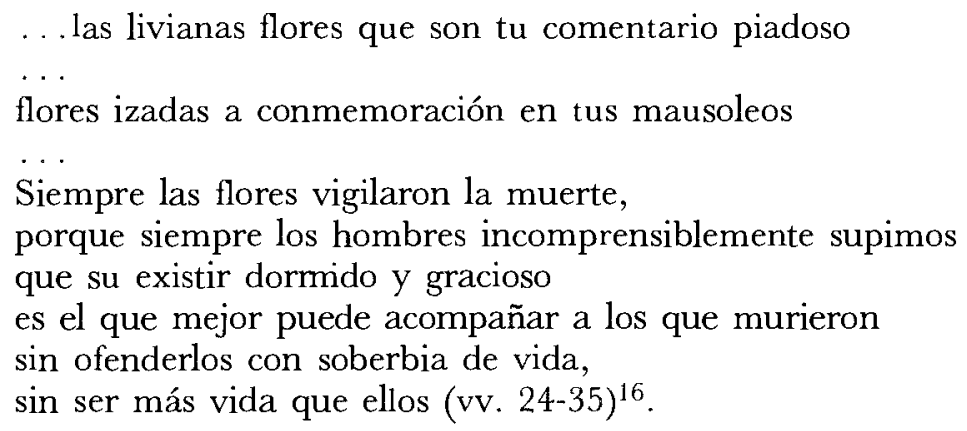

Los versos de "Muertes de Buenos Aires» parecen también estar comprometidos, si bien de forma marginal, en la introducción de "el desnudo latín y las trabadas fechas fatales", rememoración, al menos parcial, de "la muerte... se disminuye a fechas y nombres, muertes de la palabra" de "La Chacarita», vv. 4749, que a su vez reescribía "los nombres de lugar y las fechas: fraudes de la palabra" de "Isidoro Acevedo", vv. 2-3 (CSM). Pero en la génesis de este verso concurre en primer lugar "el árido latín" que concluye la existencia de Emanuel Swedenborg y la poesía (de 1966) a él dedicada $(O M)$, y, de modo específico, "A quien está leyéndome» $(O M, 1966)$, cuyos vv. 6-8 rezan así:

${ }^{16}$ Con la reescritura del v. 11 parece estar relacionada también la más tardía del v. 18, en el que el término que indica la piedra sepulcral (losas primero, bóvedas después), o bien el símbolo grave de la muerte, es sustituido por otro, más liviano, de la hiedra que esa piedra recubre: "Vibrante en las espadas y en la pasión / y dormida en la hiedra, / sólo la vida existe". 
...Te espera el mármol

que no leerás. En él ya están escritos

la fecha, la ciudad y el epitafio.

Este último texto posee, en la historia de las revisiones de «La Recoletan, una importancia muy especial; su influencia en la revisión de 1969 no se limita en efecto a la variante apenas analizada, sino que afecta a otras modificaciones relacionadas con un complejo sistema de implicaciones intertextuales. Me refiero a la operación que en EF69 afecta, primero al v. 3, que se transforma en "por tantas nobles certidumbres del polvo", variante de la lección de $L 43$ “irrealizados por tanta certidumbre de anulación", y después al verso conclusivo que pasa de "en el lugar en que han de enterrarme" (lección de E58) a "en el lugar de mi ceniza".

Las modificaciones están sin duda conectadas entre sí y la importancia de su efecto en el conjunto del poema no es despreciable: la más lexicalizada y tremenda de las metonimias de la caducidad y de la disolución del hombre, marca, en el incipit y en el explicit, una poesía sobre la muerte. Pero todavía más importante es la génesis de estos dos cambios, que parece hallarse en un grupo de textos bastante reciente, y en esa suerte de núcleo germinativo que es precisamente "A quien está leyéndome». Una indagación en el léxico proporciona un primer dato de interés: ni polvo ni ceniza, en el significado translaticio que nos interesa, se registran jamás en $F B A$ o en las dos recopilaciones sucesivas. La imagen por lo tanto no parece propia del uso léxico borgeano de estos años. Hay que esperar hasta finales de los años cincuenta para que polvo registre sus primeras apariciones en "Baltasar Gracián" (OM, 1958, "el polvo que ayer fue su figura", v. 23), "Una llave en Salónica" (OM, 1958, "Hoy que su puerta es polvo", v. 9), "El tango" (OM, 1958, "hecho de polvo y tiempo, el hombre", v. 55), casi de manera contemporánea a ceniza, que se encuentra por primera vez en "A un poeta menor de la antología" (OM, 1954, " ¿y habrá suerte mejor que la ceniza / de que está hecho el olvido?", vv. 13-14), e inmeditamente después, junto a polvo, en el ya citado "El tango" ("la ceniza que los guarda enteros", v. 30). En la poesía del decenio sucesivo - H, OM, ES- la presencia de los dos términos se hace casi obsesiva y afecta a quince textos ${ }^{17}$.

17 Polvo aparece en "Juan I, 14" (OM, 1964, "los linajes que en polvo se deshacen", v. 10), "A un poeta sajón» (OM, 1964, "Tú cuya carne, hoy dispersión y polvo", v. 1), "El alquimista» (OM, 1966, "lo convierte / en polvo, en nadie, en nada y en olvido", vv. 23-24), "El reloj de arena" ( $H$, "del polvo, del 
El conjunto de estos cambios constituye, creo, el contexto al que hay que referir las correcciones aportadas a los vv. 3 y 38 de "La Recoleta». Y me parece incluso posible identificar en los versos iniciales de "A quien está leyéndome» el núcleo central de este denso sistema de implicaciones intertextuales.

Eres invulnerable. ¿No te han dado los números que rigen tu destino certidumbre de polvo?

Estos versos reescriben en efecto el concepto expresado en el antiguo v. 3 de «La Recoleta» (pero no se olvide el hecho de que esta poesía había sido ya revisada y modificada en 1964) en una lección destinada, por decirlo de alguna manera, a ser restituida al texto original, en ocasión de la revisión de EF6918.

Este último caso tiende ya a sobrepasar el ámbito de la influencia de la escritura sobre la reescritura, y postula una investigación suplementaria que verifique si esta opera prima, de la que Borges no se llega a desprender de hecho nunca y cuya gestación se enreda con el resto de su producción, no sirve también a su vez

azar y de la nada" v. 20), "Alguien" (OM, 1966, "en la muerte para siempre seremos / cuando el polvo sea polvo", vv. 29-30). Ceniza se rastrea en "Soneto del vino" (OM, 1966, "ver mi propia historia / como si ésta ya fuera ceniza en la memoria.", vv. 13-14), "Ewigkeit» (OM, 1964, "Torne a cantar la pálida ceniza, / los fastos de la muerte", vv. 5-6), "Oda escrita en 1966» (OM, 1966, " los que prodigaron su bélica ceniza / por los campos de América", vv, 5-6), “Junín» (OM, 1967, “¿Me oyes, / sombra o ceniza última”, vv. 6-7), "Los gauchos» ( $E S$, "Su ceniza está perdida en remotas regiones del continente", v. 18), "Dos versiones de Ritter, Tod und Teufel" (ES, "Yo seré la ceniza y la tiniebla' II, v. 16). En el mismo contexto las dos palabras aparecen, además de en "El tăngo" en "A una espada en York Minster» $(O M, 1966$, "el hombre fuerte, / hoy polvo", vv. 1-2; "Soy un instante / y el instante ceniza", vv. 12-13) y "Rubaiyat" ( $E S$, "Torne a afirmar que el fuego es la ceniza, / la carne el polvo', vv. 5-6). Referible a este mismo cuadro es por fin la variante de $E 64$ en el v. 9 de "Inscripción sepulcral", que pasa de "Hoy es orilla de tanta gloria el olvido" a "Hoy es un poco de ceniza y de gloria".

18 Señalo marginalmente otro interesante detalle de la historia de estos versos: la lección "los números que rigen tu destino" no es la original, sino una variante introducida en el curso de la revisión de $E 74$. Antés de esta fecha dicho verso se presentaba en la versión original de La Nación de enero de 1966, o sea "los númenes que rigen tu destino", sin embargo, y esto es lo más interesante, el abandono de númenes es sólo provisional; no habrá pasado un año cuando el verso sea reutilizado en "La cierva blanca" $(R P)$ : "Los númenes que rigen este curioso mundo / me dejaron soñarte pero no ser tu dueño" (vv. 9-10). 
de output para la nueva producción. El tema está conectado sólo de forma marginal con los problemas inherentes a las variantes, y es mucho más pertinente al interesantísimo fenómeno de la autocita y de la reutilización interna del material poético; sin embargo, como conclusión del cuadro trazado, no me parece fuera de lugar mostrar algunos casos que documentan, con formas diferentes entre sí, una influencia del trabajo de reelaboración constante que afecta a $F B A$, en textos ulteriores.

Con la trayectoria evolutiva del ya citado v. 8 de «Final de año", que en EF69 pasa de "nos hacen aguardar las doce campanadas oscuras" a "nos obligan a esperar / las doce irreparables campanadas" me parece que deben ir relacionados pasajes de dos textos de $C$ (1981), o sea el v. 18 de «Shinto», que recupera la lección original y reescribe: "contar las doce campanadas oscuras", y el inicio de la prosa poética "Dos formas del insomnio", que cambia muy poco la variante de $E F 69$ retomando también elementos del contexto próximo: “¿Qué es el insomnio? /.../ Es temer y contar en la alta noche las duras campanadas fatales". El incipit de «El sueño" $(R P)$ : "Cuando los relojes de la media noche prodiguen / un tiempo generoso"' es una clara cita de los vv. 24-26 de "Caminata", ya modificados en 1969 ("En la cóncava sombra / vierten un tiempo vasto y generoso / los relojes de la medianoche magnífica"). Del mismo modo la "tarde gastada" de "Heráclito", v. $7(E S)$ cita la "noche gastada" introducida en E64 en el v. 54 de "Amanecer"; y los versos "No eres hoy la ceniza. Eres la gloria" de "A John Keats", v. 14, y "la gloria, que es estrépito y ceniza" de "Los gauchos", v. 24 (OT) repiten la reelaboración (E64) del verso final de "Inscripción sepulcral", "Hoy es un poco de ceniza y de gloria". De manera parecida, también la reelaboración de los vv. 15-18 de "Las calles": "porque millares de almas singulares las pueblan / únicas ante Dios y en el tiempo", está emparentada con los vv. 13-14 del "Poema de la cantidad» (OT): "Acaso cada hormiga que pisamos / es única ante Dios, que la precisa"; y a la modificaión (de EF69) del v. 31 de "La Recoleta», que pasa de "viento rico en pájaros que sobre las ramas ondea" a "viento con pájaros que sobre las ramas ondea", se debe al v. 10 de "East Lansing" (OT): "viento con pájaros que ignoro". Se trata en resumidas cuentas de continuos trasvases entrecruzados entre escritura nueva y escritura renovada; por lo que si es verdad que el "río de Heráclito" de "Final de año" invade, por decirlo de aigún modo, $F B A$, proveniendo de territorios ulteriores, no lo es menos que de los versos de "Benarés", "y anuncia a la ciudad de 
NRFH, XLI INTERTEXTUALIDAD Y SISTEMA EN LAS VARIANTES DE BORGES 537

los muchos dioses / la soledad de Dios", introducidos en EF69, provienen otros, primero de "Alhambra" $(H N)$ "la plegaria / dirigida a un Dios que está solo" (vv. 8-9), y después de «Ronda» $(C)$ "un terrible Dios, que está solo" (v. 7).

Borges quiso que el nuevo Fervor de Buenos Aires de 1969 concluyera con un texto ya incluido, un par de años antes, en $\mathrm{El}$ otro, el mismo. Se trata de «Líneas que pude haber escrito y perdido hacia 1922». La decisión no pudo ser más feliz. «Líneas» es un híbrido fascinante de versos que con verosimilitud Borges habría podido escribir y extraviar en los años veinte, y de otros que en modo alguno habría podido escribir en aquella época. Y es además respecto a lo que declara el título, una clamorosa falsificación, pero por ello constituye la más adecuada metáfora, y el más digno sello final, de este híbrido que hoy es Fervor de Buenos Aires.

Tommaso Scarano Università di Pisa 
